\title{
Diş Hekimliği Uzmanlık ve Son Sınıf Öğrencilerinin Radyasyondan Korunma ve Radyasyonun Biyolojik Etkileri Konusundaki Farkındalığının Değerlendirilmesi
}

\author{
Melike BAŞARAN 國, Esin BOZDEMIR [i] $^{2}$
}

Öz

Amaç: Bu çalışmanın amacı diş hekimliği uzmanlık öğrencileri ve diş hekimliği öğrencilerinin radyasyondan korunma, radyasyonun etkileri ile ilgili farkındalığının ve bilgi düzeyinin değerlendirilmesidir.

Gereç ve Yöntemler: Çalışmaya 103 son sınıf diş hekimliği öğrencisi ve farklı bölümlerde görev yapan 103 uzmanlık öğrencisi katıldı. Katılımcılara radyasyondan korunma, radyasyonun biyolojik etkileri ile ilgili bilgi düzeyini ölçmeyi amaçlayan, 'Doğru/Yanlış ve Bilmiyorum' seçenekleri bulunan 18 soruluk anket uygulandı. Çalışma sonucunda elde edilen sonuçlara göre iki grup arasında karşılaştırma yapıldı. Bulgular istatistiksel olarak değerlendirildi.

Bulgular: Katılımcıların büyük çoğunluğu genel radyasyon bilgisi ve radyasyondan korunma ile ilgili soruları doğru yanıtladı. Bir adet periapikal radyograftan alınan radyasyon dozunun güvenilir ve sağlığa zararlı olmadığı ifadesini yanlış yanıtlayan uzmanlık öğrencilerinin oranı $(\% 45,6)$ öğrencilerden $(\% 39,8)$ daha fazlaydı $(p=0,255)$. Katılımcıların büyük çoğunluğu hamile hastalardan kesinlikle radyografi alınmamalıdır ifadesine 'yanlış' seçeneğini işaretleyerek doğru yanıtı verdi. (uzmanlık öğrencileri \%89,3, öğrenciler \%91,3) (p>0,05). Radyasyonun sitokastik ve deterministik etkisi hakkında her iki grubun yarısına yakını yeterli bilgiye sahip değildi (öğrenciler $\% 48,5$, uzmanlık öğrencileri $\% 54,4)(\mathrm{p}>0,05)$. Konik ışınlı bilgisayarlı tomografinin avantajları hakkında öğrenciler $(\% 70,9)$ uzmanlık öğrencilerine $(\% 85,4)$ göre daha az bilgi sahibiydi.

Sonuç: Katılımcıların radyasyondan korunma ile ilgili bilgi düzeyi yeterliyken, radyasyonun etkileri hakkında bilgi düzeyi orta seviyedeydi. Bilgi düzeyinin ve farkındalığın artması için; diş hekimliği eğitimi boyunca radyasyonun biyolojik etkileri hakkındaki bilgiler daha fazla vurgulanabilir, mezun diş hekimlerine ise hatırlatma amaçlı eğitimler veya seminerler verilebilir.

Anahtar Kelimeler: Anket; diş hekimliği; radyasyondan korunma; radyoloji; X-1şınları.

\section{Evaluation of the Awareness of Dentistry Specialist and Senior Students on Radiation Protection and Biological Effects of Radiation}

\begin{abstract}
Aim: The aim of this study was to evaluate dental specialty students and dentistry students' knowledge and awareness about radiation protection and radiation effects.

Material and Methods: One hundred-three senior dentistry students and 103 specialist students working in different departments participated in this study. A questionnaire consisted of 18 questions with "True / False and Don't Know" options that were related to radiation protection and the biological effects of radiation options were applied to the participants. A comparison was made between the two groups according to the responses of the study. Results were evaluated statistically.

Results: The majority of the participants answered correctly questions about general radiation information and radiation protection. The proportion of specialists $(45.6 \%)$ who answered wrongly the statement that radiation dose associated with one periapical radiograph is absolutely safe and has no hazard on health was higher than students (39.8\%) $(p=0.255)$. The majority of the participants answered correctly by choosing the 'false' option the question that dental radiographs are entirely contraindicated for pregnant patients (specialists $89.3 \%$, students $91.3 \%)(\mathrm{p}>0.05)$.
\end{abstract}

1 Kütahya Sağlık Bilimleri Üniversitesi, Diş Hekimliği Fakültesi, Ağız, Diş ve Çene Radyolojisi Anabilim Dalı, Kütahya, Türkiye 2 Süleyman Demirel Üniversitesi, Diş Hekimliği Fakültesi, Ağız, Diş ve Çene Radyolojisi Anabilim Dalı, Isparta, Türkiye

Sorumlu Yazar / Corresponding Author: Melike BAŞARAN, e-mail: basarannm@gmail.com

Geliş Tarihi / Received: 25.06.2020, Kabul Tarihi / Accepted: 09.02.2021 
Nearly half of both groups have insufficient information about the stochastic and deterministic effects of radiation (specalist 54.4\%, students 48.5\%) ( $>>0.05)$. Students (70.9\%) had less information about the advantages of cone-beam computed tomography than specialists (85.4\%).

Conclusion: While the participants' knowledge about radiation protection was sufficient, the knowledge about the radiation effects was moderate. In order to increase knowledge and awareness of radiation effects, radiation information can be emphasized more during dentistry education and seminars related to radiation may be given graduate dentists.

Keywords: Dentistry; questionnaire; radiology; radiation protection; X-rays.

\section{GÍRIŞ}

İnsanlar evrenin oluşumundan beri radyasyonla iç içedir. Partikül ve elektromanyetik olmak üzere 2 formda bulunan radyasyon, enerjinin uzay ve madde boyunca iletilmesi olarak tanımlanır. Doğal radyoaktivite ve radyasyon tedavisi hem partikül hem de elektromanyetik radyasyonu içerirken, oral ve maksillofasiyal radyoloji sadece elektromanyetik radyasyon içerir. Toprakta bulunan radyoaktif ürünler (radyum, toryum, uranyum gibi), radon gazı, güneşten gelen kozmik 1şınlar ve vücudumuzda bulunan potasyum-40, karbon-14, radyum gibi elementler insanları doğal radyasyon yoluyla radyasyona maruz birakır (1-3).

Radyasyon, taşıdığı enerjiye göre iyonlaştırıcı ve iyonlaştırıcı olmayan olarak iki kısma ayrılır. İyonlaştırıcı radyasyon, etkileşime girdiği maddelerde iyon oluşturabilen radyasyon türüdür. $\mathrm{Bu}$ radyasyon türü, yapay radyasyon kaynakları arasında en büyük paya sahip olup, dental radyolojide kullanılan X-1şınları da iyonlaştırıcı radyasyon çeşitlerindendir. Dolayısıyla X1şınları da canlılar üzerinde doğrudan ya da dolaylı yollardan biyolojik etkiler meydana getirebilir $(2,3)$.

Radyolojik muayene; klinik diş hekimliği uygulamalarının ayrılmaz bir parçasıdır ve anamnezi alınan ve muayenesi yapılan hastalarda, radyolojik muayene ile hastalığın varlığı ve boyutu belirlenir. Bunun yanı sıra radyasyonun tanısal diş hekimliğinde kullanımı sonucu hastalar ve klinik personel X-1şınlarına maruz kalır. Dental radyografilerden alınan doz, tıbbi radyografilerden alınan etkin dozun yaklaşık \%2,5'ini oluşturmaktadır. Her ne kadar dental radyografilerden radyasyona maruz kalma oranı düşük olsa da, radyolojik değerlendirme hastaya zarardan çok yarar sağlamalı ve ALARA (As Low As Reasonably Achievable) prensibine göre mümkün olan en düşük doz kullanılarak, hastaya en uygun radyografik teknikle görüntüleme yapılmalıdır (4). Hastalar, radyoloji çalışanları, öğrenciler ve doktorlar üzerinde yapilan; radyasyonun biyolojik etkileri, radyasyondan korunma ile ilgili farkındalığı ve bilgi düzeyini ölçmeyi amaçlayan birçok anket çalışması mevcuttur. Furmaniak ve arkadaşları (5) çalışmalarında; diş hekimleri, diş hekimliği öğrencileri, röntgen teknisyenleri ve tıbbi görüntüleme öğrencilerinin radyasyondan korunma ve radyobiyolojik etkiler hakkındaki bilgi düzeylerinin yetersiz olduğunu bildirmiştir.
Enabulele ve arkadaşlarının (6) diş hekimliği öğrencilerine yaptıkları anket çalışmasında, öğrencilerin radyobiyoloji hakkındaki bilgileri orta seviyede, radyasyondan korunma ile ilgili bilgileri ise yetersiz bulunmuştur.

Yazarların bilgisi dahilinde; ülkemizde diş hekimliği öğrencileri ve diş hekimliği uzmanlık öğrencileri üzerinde radyasyondan korunma, radyasyonun biyolojik etkileri hakkında bilgi düzeyini ölçen bir çalışma bulunmamaktadır. Bu bağlamda bu çalışmanın amacı; diş hekimliği son sınıf öğrencileri ve uzmanlık öğrencilerinin, genel radyasyon bilgisi, radyasyon biyolojisi, radyasyondan korunma ve radyasyonun etkileri hakkında bilgi düzeylerinin ve farkındalıklarının değerlendirilmesidir.

\section{GEREÇ VE YÖNTEMLER}

Bu çalışmaya, aynı fakültede öğrenim gören 103 son sınıf diş hekimliği öğrencisi ve yine aynı fakültede farklı bölümlerde görev yapan (Ağız, Diş ve Çene Radyolojisi dışında) 103 uzmanlık öğrencisi dahil edildi. Bu çalışma için Süleyman Demirel Üniversitesi Tıp Fakültesi Klinik Araştırmalar Etik Kurulu Başkanlığı'ndan çalışma onayı alındı (2018/176). Katılımcılara 'Doğru/Yanlış ve Bilmiyorum' seçenekleri bulunan 18 soruluk anket uyguland. Anketin ilk kısmında katılımcıların yaş, cinsiyet, uzmanlık bölümü gibi demografik özellikleri kaydedildi ve daha sonra genel radyasyon bilgisi, radyasyonun biyolojik etkileri, radyasyon dozları, radyasyondan korunma ile ilgili bilgi düzeyini ölçmeyi amaçlayan sorular soruldu.

\section{İstatistiksel Analiz}

Çalışma sonucunda elde edilen sonuçlarla iki grup arasında karşılaştırma yapıldı. Verilerin istatistiki değerlendirilmesinde SPSS paket programı (SPSS version 20, SPSS Inc, Chicago, ABD) kullanıldı. Veri analizi Pearson ki kare testiyle yapıldı ve $p$ değeri 0,05 'ten küçük olan sonuçlar istatistiksel olarak anlamlı kabul edildi.

\section{BULGULAR}

$\mathrm{Bu}$ çalışma dahilinde toplam 206 kişinin cevapları değerlendirildi. Çalışmaya katılan grupların yaş ortalamaları; uzmanlık öğrencilerinde $27,38 \pm 3,33$ ve son sınıf öğrencilerinde $23,37 \pm 1,34$ 'di. Her iki grupta da kadınlar çoğunluktaydı (uzmanlık öğrencilerinde \%65, öğrencilerde \%65,7).

Katılımcıların büyük çoğunluğu (uzmanlık öğrencilerinin yüzdesi \%98,1'i, öğrencilerin \%90,3'ü) 'Diagnostik radyolojide mümkün olan en düşük dozun kullanılmasını öngören ilke ALARA (As Low As Reasonably Achievable) prensibidir.' sorusunda 'doğru' seçeneğini işaretleyerek doğru yanıtı verdi. Bu soruda uzmanlık öğrencilerinin \%1,9'u, öğrencilerin \%9,7'si ‘bilmiyorum' seçeneğini işaretledi. $(p=0,640)$.

Uzmanlık öğrencilerinin yarısından fazlası $(\% 54,4)$, öğrencilerin ise yarısına yakını $(\% 48,5)$ 'deterministik etki her dozda gözlenebilen etkidir. İnsanlarda uzun süre düşük dozda radyasyon maruziyeti sonucunda kanser, genetik hasarlar gibi deterministik etkiler görülür' sorusuna 'doğru' seçeneğini işaretledi ( $p=0,411)$. (Grafik 1) 
Organizmanın tamamının radyasyona maruz kalması belli bir bölgenin 1şınlanmasından daha az zarar verir.' sorusunda uzmanlık öğrencilerinin $\% 71,8$ 'i, öğrencilerin ise \%78,6'sı soruya doğru yanıtı verdi ve bu soru için cevaplar arasındaki fark istatistiksel olarak anlamlıydı. $(\mathrm{p}=0,042)$ (Tablo 1)

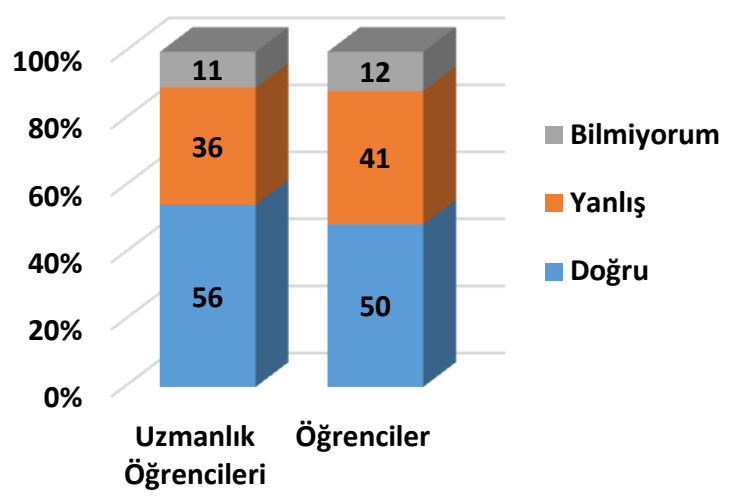

a

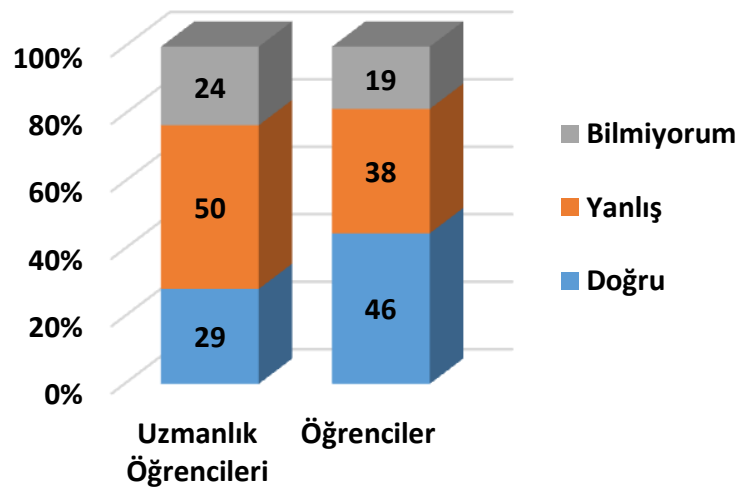

b

Grafik 1. 'Deterministik etki her dozda gözlenebilen etkidir. İnsanlarda, uzun süre düşük dozda radyasyona maruziyet sonucunda kanser, genetik hasarlar gibi deterministik etkiler görülür.' (a) ve 'Normal şartlarda diş hekimliğinde kullanılan tanısal radyolojide stokastik etki oluşur.' (b) sorularına verilen cevapların sayısı ve gruplar arasında dağılımı

Tablo 1. Radyasyondan korunma, genel radyasyon bilgisi ile ilgili sorulara verilen cevapların gruplar arasında dağılımı

\begin{tabular}{|c|c|c|c|c|c|}
\hline & \multicolumn{2}{|c|}{ Doğru } & \multicolumn{2}{|c|}{ Yanlış } & \multirow[b]{2}{*}{ p değeri } \\
\hline & $\begin{array}{c}\text { Uzmanlık } \\
\text { ögrrencileri } \\
\text { n }(\%) \\
\end{array}$ & $\begin{array}{c}\text { Öğrenciler } \\
\mathbf{n}(\%) \\
\end{array}$ & $\begin{array}{c}\text { Uzmanlık } \\
\text { ögrrencileri } \\
\text { n }(\%) \\
\end{array}$ & $\begin{array}{c}\text { Öğrenciler } \\
\text { n }(\%) \\
\end{array}$ & \\
\hline $\begin{array}{l}\text { Hamile hastalardan kesinlikle } \\
\text { radyograf alınmamalıdır. }\end{array}$ & $92(89,3)$ & $94(91,3)$ & $11(10,7)$ & $9(8,7)$ & 0,965 \\
\hline $\begin{array}{l}\text { Çocuk hastalarda radyograf } \\
\text { çekimi sırasında mutlaka kurşun } \\
\text { boyunluk } \\
\begin{array}{l}\text { Böylece tiroid dozıllanılmalıdır. } \\
\text { oranında azaltılır. }\end{array} \\
\text { oran } \% 92 \\
\end{array}$ & $90(87,4)$ & $98(95,1)$ & $13(12,6)$ & $5(4,9)$ & 0,384 \\
\hline \begin{tabular}{lrr}
\multicolumn{2}{l}{ Radyasyon } & \multicolumn{2}{c}{ sonucu meydana } \\
gelen kanser & \multicolumn{2}{c}{ oluşma riski } \\
tekrarlanan & \multicolumn{2}{c}{ radyasyon } \\
işınlamalarılyla & orantıll & olarak \\
artar. & & \\
\end{tabular} & $78(75,7)$ & $78(75,7)$ & $25(24,3)$ & $25(24,3)$ & 0,268 \\
\hline $\begin{array}{l}\text { Organizmanın tamamının } \\
\text { radyasyona maruz kalması belli } \\
\text { bir bölgenin ışınlanmasından } \\
\text { daha az zarar verir. }\end{array}$ & $74(71,8)$ & $81(78,6)$ & $29(28,2)$ & $22(21,4)$ & $0,042 *$ \\
\hline $\begin{array}{l}\text { Hastanın muayenesi yapılmadan } \\
\text { hastadan radyograf alınabilir. }\end{array}$ & $97(94,2)$ & $93(90,3)$ & $6(5,8)$ & $10(9,7)$ & $0,001^{*}$ \\
\hline $\begin{array}{l}\text { Konik ışınlı bilgisayarlı tomografi } \\
\text { daha az radyasyon dozu vermesi, } \\
\text { daha ucuz olması ve ışınlama } \\
\text { zamanının daha kısa olması } \\
\text { nedeniyle bilgisayarlı tomografiye } \\
\text { göre daha avantajlıdır. }\end{array}$ & $88(85,4)$ & $56(54,4)$ & $15(14,6)$ & $47(45,6)$ & $0,004 *$ \\
\hline
\end{tabular}

Pearson ki-kare testi $(* \mathrm{p}<0,05)$

Dijital radyografların avantajı hakkındaki 'dijital radyografi, konvansiyonel radyografiye göre daha az radyasyon verir' sorusunda her iki grubun da büyük çoğunluğu (uzmanlık öğrencileri \%83,5, öğrenciler
\%86,4) 'doğru' seçeneğini işaretledi. Bu soruda uzmanlık öğrencilerinin \%11,7'si 'yanlış', \%4,9'u 'bilmiyorum' seçeneğini işaretlerken, öğrencilerin \%2,9'u 'yanlış', \%10,7'si ‘bilmiyorum' seçeneğini işaretledi. ( $p=0,397)$. 
'Yüksek hızlı filmler daha fazla radyasyon verir' sorusunda 'doğru', 'yanlış', 'bilmiyorum' seçeneğini işaretleyenlerin oranı sırasıyla uzmanlık öğrencilerinde $\% 16,5, \% 76,7$ ve $\% 6,8$ iken bu oran öğrencilerde sirasiyla $\% 18,4, \% 66$ ve $\% 15,5$ 'ti. Bu soruya verilen cevaplar arasındaki fark istatistiksel olarak anlamlıdı $(\mathrm{p}=0,035)$.

Doğal radyasyon hakkındaki 'tüm yüzey kaya ve toprak parçalarından, yap1 malzemelerinden ortama salınan radon; doğal radyasyonun en önemli kaynağıdır.' sorusuna katılımcıların büyük çoğunluğu (uzmanlık öğrencisi \%86,4, öğrenciler \%88,3) 'doğru' seçeneğini işaretledi.

Diş hekimliğinde radyasyonun biyolojik etkileriyle ilgili 'normal şartlarda diş hekimliğinde kullanılan tanısal radyolojide stokastik etki oluşur.' ifadesinde uzmanlık öğrencilerinin \%48,5'i 'yanlış', \%23,3'ü 'bilmiyorum' seçeneğini işaretlerken, öğrencilerin \% 44,7'si 'doğru', $\% 18,4$ 'ü 'bilmiyorum' seçeneğini işaretledi. Bu soruya verilen cevaplar arasındaki farklılık anlamlı değildi ( $\mathrm{p}=0,537)$. (Grafik 1)

'Radyasyona en duyarlı hücreler; mitotik aktivitesi az olup olgunlaşmamış hücrelerdir.' sorusunda katılımcıların çoğunluğu (uzmanlık öğrencisi \%76,7, öğrenciler \% 79,6) 'yanlış' seçeneğini işaretledi. Bu soruda uzmanlık öğrencilerinin \%20,4'ü 'doğru', \%2,9'u 'bilmiyorum' seçeneğini işaretlerken, öğrencilerin \%14,6's1 'doğru', \%5,8'i 'bilmiyorum' seçeneğini işaretledi. Bu sorunun cevapları arasındaki farklılık istatistiksel olarak anlamlı bulunmadi $(\mathrm{p}=0,343)$.

Radyasyonun zararları ile ilgili sorulan 'bir adet periapikal radyograftan alınan radyasyon dozu tamamen güvenilirdir ve sağlığa zararlı değildir.' sorusunda, uzmanlık öğrencilerinin \%45,6's1 'doğru', \%5,8'i 'bilmiyorum' seçeneğini işaretlerken, öğrencilerin \%50,5'i 'hayır', \%9,7'si 'bilmiyorum' seçeneğini işaretledi. Bu soruya verilen yanıtlar arasındaki farklılık istatistiksel olarak anlamlı değildi $(p=0,255)$. (Grafik 2)

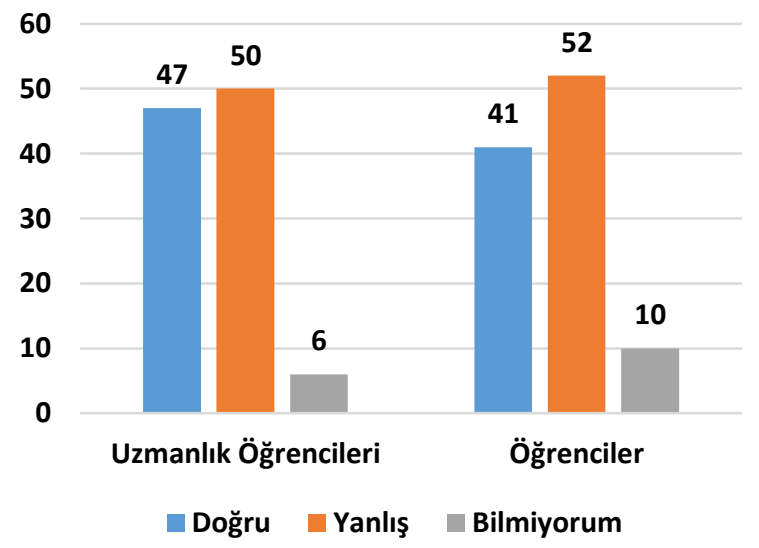

Grafik 2. "Bir adet periapikal radyograftan alınan radyasyon dozu tamamen güvenilirdir ve sağlığa zararlı değildir." ifadesine uzmanlık öğrencileri ve öğrenciler tarafından verilen cevapların sayısı ve dağılımı.

'Çocuklar ve fetüs radyasyona daha hassastır" sorusuna uzmanlık öğrencilerinin hepsi 'doğru' seçeneğini işaretlerken, öğrencilerin \%2,9 u 'yanlış' seçeneğini işaretledi.
Radyasyondan korunma ve genel radyasyon bilgisi ile ilgili bazı soruların cevapları "bilmiyorum" seçeneğini işaretleyenlerin yanlış cevap verdiği kabul edilerek düzenlendi ve cevapların gruplar arasındaki dağılımı Tablo 1'de gösterildi.

Katılımcılara konik 1şınlı bilgisayarlı tomografinin avantajları hakkında sorulan 'konik 1şınlı bilgisayarlı tomografi, daha az radyasyon dozu vermesi, daha ucuz olması ve ışınlama zamanının daha kısa olması nedeniyle bilgisayarlı tomografiye göre daha avantajlıdır.' öğrencilerin \%45,6'sının cevabı yanlışken, uzmanlık öğrencilerinin \%85,4'ünün cevabı doğruydu. Bu soruda 'bilmiyorum' seçeneğini işaretleyenlerin cevabı yanlış kabul edilerek analiz yapıldı ve verilen yanıtlar arasındaki farklılı istatistiksel olarak anlamlı bulundu. $(\mathrm{p}=0,004)$ (Tablo 1)

\section{TARTISMA}

X-1şınları birçok alanda olduğu gibi dental görüntülemede de sıklıkla kullanılmaktadır. İyi bir radyolojik uygulama; teşhis amacına uygun en hızlı görüntü reseptörünün ( $F$ hılı film veya dijital film) ve kolimatörün kullanılması; ışınlanma ve film işleme tekniklerinin uygun olması; kurşun önlük ve tiroid koruyucu kullanılarak verilen radyasyon dozunun azaltılması ve teşhise varabilmek için gerekli görüntü sayısının en az düzeyde tutulması gibi basamakları içerir (4). Diş hekimliğinde, hastaların maruz kaldığı radyasyon dozunun medikal uygulamalara oranla daha az olması çalışanları radyasyondan korunma kurallarını önemsememeye sevk edebilir ancak dünya genelindeki radyolojik uygulamaların \%21'ini diş hekimliği radyolojisi oluşturmaktadır. Bu yüzden hastanın, hekimin ve çalışan personelin aldığı dozun en aza indirilmesi için mümkün olan en düşük doz ilkesini savunan ALARA prensibine uyulması gerekmektedir. Çeşitli ülkelerde radyasyon farkındalığı ile ilgili yapılan çalışmalarda ALARA prensibinin ne anlama geldiğini bilen diş hekimliği öğrencisi oranı \%17-\%40 arasında değişmektedir (6-8). Bu çalışmada ise katılımcıların ALARA prensibi ile ilgili bilgi düzeyinin diğer çalışmalardaki katılımcılara oranla oldukça yüksek olduğu görülmüştür. (uzmanlık öğrencileri \%98,1, öğrenciler \% 90,3).

Radyasyona maruziyet sonucunda, uygulanan doza göre deterministik ve stokastik etkiler ortaya çıkar. Deterministik etkide etkinin şiddeti doza bağlıdır ve eşik değerin altındaki dozlarda deterministik etki görülmez. Sitokastik etki, şiddetinden ziyade ortaya çıkma olasılığ doza bağlı olan değişikliklerdir. Sitokastik etki ya vardır ya da yoktur, eşik dozdan bağımsızdır. Diş hekimliği radyolojisinde ise sitokastik etki oluşur (9). Arnout ve Jafar'ın (8) çalışmasında deterministik ve sitokastik etki hakkında doğru bilgi sahibi olan katılımcı oranı \%30,2'yken, Prabhat ve arkadaşlarının (10) çalışmalarında bu oran \%90'lardadır. Bu çalışmada ise katılımcıların radyasyonun biyolojik etkileri hakkındaki bilgi seviyesi orta düzeydeydi. Uzmanlık öğrencilerinde daha yüksek olmak üzere, katılımcıların yarısı deterministik etkinin tanımını bilmezken (uzmanlık öğrencileri \%54,4, öğrenciler \%48,5), diş hekimliğinde sitokastik etkinin oluşacağını bilen öğrenci sayısı (46 kişi, 
\%44,7) uzmanlık öğrencilerinden (29 kişi \%28,2) daha fazlayd1.

Radyasyonun her dozu zararlıdır ve tekrarlayan 1şınlamalar sonucunda hastalar daha çok doza maruz kalır. Furmaniak ve arkadaşlarının (5) çalışmasında bir adet periapikal radyograftan alınan radyasyon dozunun sağlığa zararlı olmadığı sorusuna diş hekimlerinin \%28'i, diş hekimliği öğrencilerinin ise \%23'ü doğru yanıtı vermiştir. Bu çalışmada ise bahsi geçen çalışmadan daha yüksek olarak katılımcıların yarısı (uzmanlık öğrencileri $\% 48,5$, öğrenciler $\% 50,5$ ) doğru yanıtı verdi.

Endikasyonu olması halinde; hamile hastalardan kurşun önlük kullanılıp en uygun radyografi yöntemi seçilerek dental radyograf alınabilir. Bunun yanı sira hasta bilgilendirilip onamı da alınmalıdır (2). Arnout ve Jafar'ın (8) çalışmasında hamile hastalardan kesinlikle radyograf alınmamalıdır sorusuna klinik öğrencilerinin \%46'sı doğru yanıtı vermişlerdir. Sultan ve arkadaşları (11) ile Furmaniak ve arkadaşlarının (5) çalışmalarında ise diş hekimlerinin, öğrencilere göre bu soruya daha fazla oranda doğru yanıtı verdiği rapor edilmiştir. (sırasıyla diş hekimleri \%69,3-\%54,7, öğrenciler \%34,9$\% 45,2$ ) Bu çalışmada ise yine diğer çalışmalardan daha yüksek olarak katılımcıların yaklaşık \%90’1 bu soruya doğru yanıt verirken, bu oran öğrencilerde daha yüksekti. Radyolojik uygulamalar, klinik muayeneyle birlikte tanıya yardımcı yöntemlerdir. Radyolojik uygulamada esas, hastaların gereksiz yere X-ışınına maruz kalmasının önüne geçmektir. Bu amaçla hastanın anamnezi alınıp, şikayetinin kaynağı tespit edildikten sonra hasta uygun radyografi yöntemi ile görüntülenmeli ve hastanın önceden çekilmiş röntgenlerinin bulunup bulunmadığı da sorgulanmalıdır. Çalışmamızın sonuçlarına göre katılımcıların \%90'1 muayene yapmadan radyograf almayı doğru bulmamıştır. Radyasyon farkındalığı ile ilgili yapılan çalışmalardaki katılımcı gruplarının, sayısının ve bilgi düzeyinin farklılığı, ülkeler arasındaki eğitim-öğretim müfredatının, materyallerinin ve imkânlarının değişkenlik göstermesi çalışma sonuçlarının farklı bulunmasında etkili olmuş olabilir.

Konik 1şınlı bilgisayarlı tomografi (KIBT), günümüz diş hekimliğinde sıklıkla kullanılan, baş-boyun bölgesinde süperpozisyon ve magnifikasyonu ortadan kaldırarak üç boyutlu görüntülemeye olanak sağlayan bir görüntüleme yöntemidir. Bilgisayarlı tomografilerdeki gibi çoklu rotasyonlar yerine $\mathrm{KIBT}, 360^{\circ}$ tek bir rotasyonla sşınlama süresini kısaltır ve böylece hastaya daha az X-1şını ulaşır. Ayrıca KIBT, bilgisayarlı tomografiye göre dört kat daha dar bir alanın görüntülenmesine imkan sağlar. Konvensiyonel bilgisayarlı tomografi cihazlarına göre KIBT'in efektif dozu \%98 daha azdır (12). Lavanya ve arkadaşları ile Ghonchech ve arkadaşlarının mezun diş hekimlerinin katılımıyla yaptıkları çalışmalarında, KIBT'nin efektif dozu ilgili katılımcıların bilgi seviyesi Lavanya ve arkadaşlarının çalışmasında yetersiz bulunurken; Ghonchech ve arkadaşları bu oranı daha yüksek bulmuştur. $(13,14) \mathrm{Bu}$ çalışmada ise, uzmanlık öğrencilerinin büyük çoğunluğu ile öğrencilerin yaklaşık yarısı KIBT ile ilgili doğru bilgiye sahipti ve uzmanlık öğrencilerinin KIBT ile ilgili bilgi düzeyi öğrencilere oranla daha yüksekti. Uzmanlık öğrencilerinin, dişte uzmanlık sınavında başarılı olabilmek için lisans eğitim bilgilerini tazelemeleri ve mesleki deneyimlerinin ögrencilere göre daha fazla olması uzmanlık öğrencilerinin bu soruda bilgi düzeyinin daha yüksek bulunmasına neden olmuş olabilir. Bunun yanı sıra lisans eğitiminde KIBT ile ilgili doğru bilgilendirmeye daha fazla yer verilmesi öğrencilerin KIBT ile ilgili bilgi seviyesini artırabilir.

\section{SONUÇ}

$\mathrm{Bu}$ çalışmanın sonuçlarına göre; öğrencilerin ve uzmanlık öğrencilerinin genel radyasyon bilgisi ve radyasyondan korunma ile ilgili bilgi ölçen sorulara büyük oranda doğru yanıt verdiği saptandı ancak radyasyonun etkileri hakkındaki bilgi düzeyi her iki grupta da orta seviyedeydi. Radyasyonun biyolojik etkilerinin bilinmesi hastaların gereksiz radyasyona maruz kalmaması için önemlidir. Bilgi düzeyinin ve farkındalığın artması için; diş hekimliği eğitimi boyunca radyasyonun biyolojik etkileri hakkındaki bilgiler daha fazla vurgulanabilir, mezun olmuş diş hekimlerine ise hatırlatma amaçlı eğitimler veya seminerler verilebilir.

Çıkar Çatışması: Yazarlar arasında herhangi bir çıkar çatışması bulunmamaktadır.

Yazarların Katkıları: Fikir/Kavram: M.B.; Tasarım: M.B., E.B.; Veri Toplama ve/veya İşleme: M.B., E.B.; Analiz ve/veya Yorum: M.B.. E.B.; Literatür Taraması: M.B.; Makale Yazımı: M.B.; Eleştirel İnceleme: E.B.

\section{KAYNAKLAR}

1. White SC, Pharoah MJ, editors. Oral Radiology: Principles and Interpretation. 7th Ed. St Louis: Elsevier Health Sciences; 2014.

2. Harorlı A, Akgül M, Dağıstan S. Diş Hekimliği Radyolojisi Kitabı. Erzurum: Eser Ofset Matbaacılık; 2012.

3. taek.gov.tr. [İnternet]. Türkiye: [Son güncelleme tarihi: 09/06/2020; Erişim: 12/06/2020]. Erişim adresi: http://taek.gov.tr.

4. American Dental Association Council on Scientific Affairs. Dental radiographic examinations: Recommendations for patient selection and limiting radiation exposure. U.S. Department of Health and Human Services Public Health Service Food and Drug Administration. 2012; 1-21.

5. Furmaniak KZ, Kołodziejska MA, Szopinski KT. Radiation awareness among dentists, radiographers and students. Dentomaxillofac Radiol. 2016; 45(8): 15.

6. Enabulele JE, Igbinedion BO. An assessment of dental students' knowledge of radiation protection and practice. J Educ Ethics Dent. 2013; 3(2): 54-9.

7. Hussein RE, Hashim NT, Awooda EM. Knowledge, awareness and practice of sudanese dentists towards oral radiology and protective guidelines. IOSR- J Dent Med Sci. 2016; 15(10): 79-83.

8. Arnout E, Jafar A. Awareness of biological hazards and radiation protection techniques of dental imaginga questionnaire based cross-sectional study among 
saudi dental students. J Dent Health Oral Disord Ther. 2014; 1(1): 1-8.

9. White SC, Mallya SM. Update on the biological effects of ionizing radiation, relative dose factors and radiation hygiene. Aust Dent J. 2012; 57(Suppl 1): 2- 8 .

10. Prabhat M, Sudhakar S, Kumar B, Ramaraju. Knowledge, attitude and perception (KAP) of dental undergraduates and interns on radiographic protection- A questionnaire based cross- sectional study. J Adv Oral Res. 2011; 2(3): 45-50.

11. Sultan R, Parvez K, Qureshi H. Awareness about dental radiography among dental students. J Pak Dent Assoc. 2018; 27(3): 147-51.

12. Başaran M, Bozdemir E. Güncel literatür 1şı̆̆ında temporomandibular eklem rahatsızlıklarında kullanılan görüntüleme yöntemleri. Haliç Üniv Sağ Bil Der. 2020; 3(1): 15-26.

13. Lavanya R, Babu DB, Waghray S, Chaitanya NC, Mamatha B, Nithika M. A questionnaire crosssectional study on application of cbct in dental postgraduate students. Pol J Radiol. 2016; 81: 181-9.

14. Ghoncheh Z, Panjnoush M, Kaviani H, Kharazifard MJ, Zahirnia F. Knowledge and attitude of Iranian dentists towards cone-beam computed tomography. Front Dent. 2019; 16(5): 379-85. 